Conference - May. 17-20, 1993, Washington, DC

\title{
NSLS X-RAY SYSTEM RF SYSTEM UPGRADE *
}

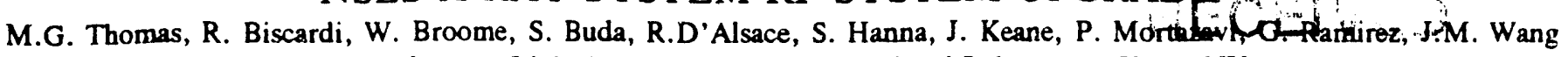
National Synchrotron Light Source, Brookhaven National Laboratory, Uptonjfy 12931993

\section{Abstract}

Presently (Dec. 1992) three RF systems power the electron beam at the NSLS X-Ray storage ring to $250 \mathrm{~mA}$ at $2.58 \mathrm{GeV}$. A fourth RF cavity and system is being installed to increase the machine reliahility over pre-shutdown operational conditions ( 3 cavities). It also permits new levels of beam intensity and energy to be achieved in the X-Ray ring. Intensities of $500 \mathrm{~mA}$ at $2.5 \mathrm{GeV}$ as well as $250 \mathrm{~mA}$ at $2.8 \mathrm{GeV}$ are anticipated. A description of the hardware, the installation and the modes of operation will be outlined in this paper. X-Ray ring operations are scheduled to resume January 1993. Injection performance and high energy reliability will also be discussed.

\section{INTRODUCTION}

The National Synchrotron Light Source (NSLS) is a national user facility in which proprietary research may be done by groups within and outside of Brookhaven National Laboratory. Two electron storage rings are currently (perating: a $750 \mathrm{MeV}$ VUV ring with 16 ports for VUV and IR research, and an X-Ray ring with 28 ports for X-Ray research.

The NSLS X-Ray ring is dedicated to the production of high brightness, synchrotron radiation that normally operates at $2.58 \mathrm{GeV}$ at $250 \mathrm{~mA}$. Power to return the energy lost to synchrotron radiation is supplied by $125 \mathrm{~kW}$ transmitters driving $52.88 \mathrm{MHz}$ resonators.

Present operation with three RF systems is at $\mathbf{2 . 5 8 4}$ $\mathrm{GeV}$ and $250 \mathrm{~mA}$ with an average lifetime that exceeds 20 hours. The radiation loss per turn is $574 \mathrm{keV}$, thus the beam power is $0.25 \mathrm{amp} \times 574 \mathrm{kV}=143.5 \mathrm{~kW}$ or $48 \mathrm{~kW}$ per cavity. The beam power to cavity copper loss ratio, $P_{b} / P_{c}=$ $48 \mathrm{~kW} / 31 \mathrm{~kW}=1.55$, and the total power per system is 79 $\mathrm{kW}$; as shown in Table 1a. With the addition of a fourth RF system, reliability can be improved in either of two modes of operation. If the excitation power of each cavity is left at 31 $\mathrm{kW}$, the beam loading is reduced to $36 \mathrm{~kW}$ each. Note, that a fault in one system still allows enough remaining power to retain circulating stored beam. However, if the power/cavity is reduced to $17.5 \mathrm{~kW}$ (same O.V.F. as 3 systems), the total power requirement is only $53.5 \mathrm{~kW}$ as shown in $1 \mathrm{~b}$.

Each RF system is capable of producing $100 \mathrm{~kW}$ of power reliably, so there is ample power for higher beam currents or higher energy operation, as mentioned above. Operation at $500 \mathrm{~mA}$ is summarized in Table 1c. The beam power to cavity power ratio is rather high for the second mode, but presently the VUV cavities are run at $P_{b} / P_{c}$ ratios greater than 7:1. This mode requires additional study. Higher energy parameters are shown in Table 1d.

* Work performed under the auspices of the U.S. Department of Energy under contract DE-AC02-76CH00016.
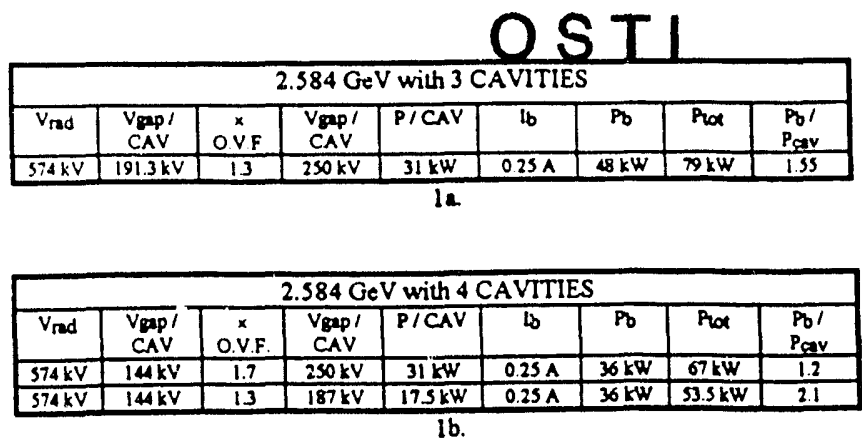

\begin{tabular}{|c|c|c|c|c|c|c|c|c|}
\hline \multicolumn{9}{|c|}{$2.5 \mathrm{GeV}$ with 4 CAVTTIES } \\
\hline $\bar{v}_{\text {rad }}$ & $\begin{array}{l}\text { Vgep } \\
\text { CAV }\end{array}$ & $\begin{array}{c}x \\
\text { o.v.f. }\end{array}$ & $\begin{array}{l}\text { Vap I } \\
\text { CAV }\end{array}$ & P/CAV & Ib & $\overline{P b}$ & Prot & $\begin{array}{l}\mathrm{Pb} / \\
\mathrm{Pal}_{\mathrm{cav}}\end{array}$ \\
\hline $503 \mathrm{kV}$ & $126 \mathrm{kV}$ & 2.0 & $250 \mathrm{kV}$ & $31 \times W$ & $0.5 A$ & $63 \mathrm{~kW}$ & 94kW & 20 \\
\hline $.503 \mathrm{kV}$ & $126 \mathrm{kV}$ & 1.5 & $187 \mathrm{kV}$ & $175 \mathrm{~kW}$ & $0.5 \mathrm{~A}$ & $63 \mathrm{~kW}$ & $80.5 \mathrm{~kW}$ & .3 .6 \\
\hline
\end{tabular}

\begin{tabular}{|c|c|c|c|c|c|c|c|c|}
\hline \multicolumn{9}{|c|}{$2.8 \mathrm{GeV}$ with $4 \mathrm{CAVTTIES}$} \\
\hline$V_{\text {rad }}$ & $\begin{array}{l}\text { Vgap } \\
\text { CAV }\end{array}$ & $\begin{array}{c}x \\
\text { O.V.F. }\end{array}$ & $\begin{array}{l}\text { Voap I } \\
\text { CAV }\end{array}$ & P/CAV & ib & $\mathrm{Pb}$ & Plot & $\begin{array}{l}P_{b l} 1 \\
P_{\mathrm{cav}}\end{array}$ \\
\hline $791 \mathrm{kV}$ & $198 \mathrm{kV}$ & 13 & $257 \mathrm{kV}$ & $33 \mathrm{~kW}$ & $0.25 \mathrm{~A}$ & $50 \mathrm{~kW}$ & $83 \mathrm{~kW}$ & 1.5 \\
\hline
\end{tabular}

Table 1

\section{CAVITY HARDWARE AND INSTALLATION}

A Varian Y-567B (4CW 100,000E) tube was chosen as the final amplifier to power the new installation. This tube has functioned reliably to above $90 \mathrm{~kW}$ in a Varian-built transmitter since 1986 (>50000 hours) in daily operations, without replacement. A new printed circuit RF processor was installed which includes all the low level processing, such as the phase and amplitude loops, signal detection and monitors, and tuning control. A frequency control loop drives the tuner to compensate for reactive beam loading. Linking to the computer is done via a newly designed VME crate, for levelsetting, monitoring, and communications with control-room operators.

The resonator is a capacitively loaded, copper-clad steel cavity, with loop coupling and a shorted loop, motordriven tuner. $80 \%$ of the total power is dissipated in the water cooled electrode which is made of OFHC copper. Due to the relatively large surface area, each cavity has a 440 lit./sec. ion pump, a $45 \mathrm{lit}$. $/ \mathrm{sec}$. Star cell ion pump and a titanium sublimation pump. Water cooled apertures were placed upstream of each RF cavity in order to intercept unwanted synchrotron radiation before impinging onto the accelerating gap surfaces. Cavity 4 installation in the beam line, paired with cavity 3 , is shown in Fig. 1.

Inner surfaces of the cavity have been coated with a 300-400 angstrom layer of titanium/titanium nitride. It was concluded during initial testing that the coating was sufficient to prevent multipactoring, but after installation, a persistent, 
DISCLAIMER

This report was prepared as an account of work sponsored by an agency of the United States Government. Neither the United States Government nor any agency thereof, nor any of their employees, makes any warranty, express or implied, or assumes any legal liability or responsibility for the accuracy, completeness, or usefuiness of any information, apparatus, product, or process disclosed, or represents that its use would not infringe privately owned rights. Reference herein to any specific commercial product, process, or service by trade name, trademark, manufacturer, or otherwise does not necessarily constitute or imply its endorsement, recommendation, or favoring by the United States Government or any agency thereof. The views and opinions of authors expressed herein do not necessarily state or reflect those of the United States Government or any agency thereof. 
low level, $2 \mathrm{~kW}$ multipactoring level still exists. Future testing of the loop window and cavity should determine the exact source of this problem.

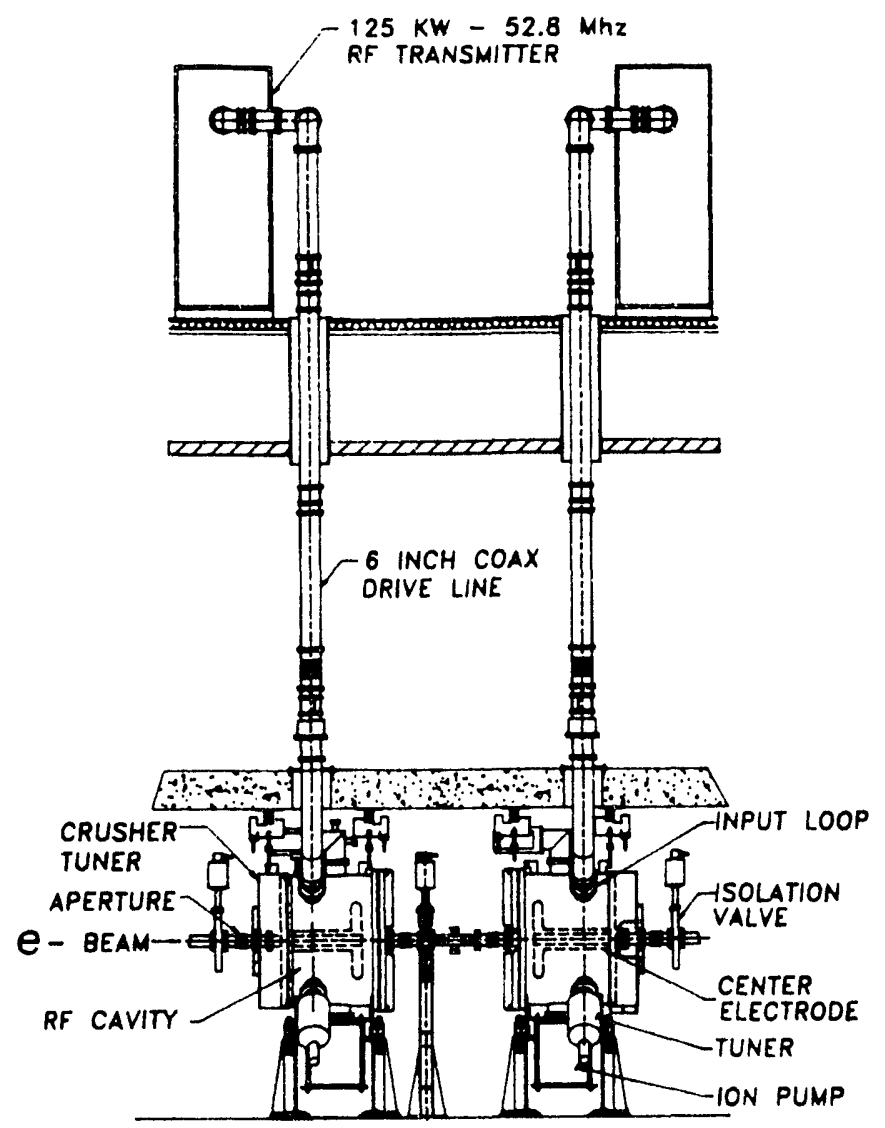

Fig. 1. System 3 and 4 RF Cavities

\section{HIGHER ORDER MODE SUPPRESSION}

Higher order modes (HOMS) are damped using five electric field probes inserted into the cavity. The probe locations provide coupling to the Homs while minimizing their effect on the accelerating mode. Each probe is terminated with a water cooled, $50 \mathrm{Ohm}$ load. The approximate shunt impedances of the HOMS were measured using on-axis $E$ and $\mathrm{H}$ field ${ }^{\prime}$ probes to obtain the undamped $\left(Q_{0}\right)$ and damped $\left(Q_{D}\right)$ quality factor of the mode. The approximate damped shunt impedance of the mode can be found by scaling the value of the shunt impedance as calculated by URMEL. This assumes that the value of $R / Q$ does not change with damping.

Another impedance measurement technique ${ }^{2,3}$ was implemented using a central wire to simulate the electron beam. This method was used to characterize the cavity modes up to $1 \mathrm{GHz}$ and confirmed the effectiveness of the damping antennae. Scattering parameters were measured using a network analyzer (HP 8510B) with a PC as a controller. System analysis based on $S$ and $T$ parameters was used to solve for the cavity impedance, $Z(\omega)$, as a function of the measured transmission response, $S_{12}(\omega)$. Search techniques were used to find the shunt resistance, $R_{s h}$, and $Q$ from the calculated $Z(\omega)$ different modes. Results for $R / Q$ showed good agreement with URMEL simulations. The values of $Q$ for undamped and damped modes for the $52 \mathrm{MHz}$ cavity were compared with the above probe technique and were in good agreement. Results of both methods for the monopole modes are summarized in Table 2 . Similar results were achieved for the dipole modes using the probe technique.

\begin{tabular}{||c|c|c|c|c|c|}
\hline \multicolumn{2}{|c|}{ Impedance Measurement } & \multicolumn{3}{|c|}{ Probe Q-Measurement } \\
\hline$f($ MHz) & $Q$ & $Q d$ & $f$ (MHz) & $Q$ & $Q d$ \\
\hline 53.235 & 10,471 & 7,598 & 52.948 & 16,100 & 13,800 \\
\hline 275.101 & 36,122 & 145.0 & 273.673 & 33,050 & 160 \\
\hline 338.092 & 26,663 & -- & 338.002 & 26,500 & 30 \\
\hline 387.249 & 32,385 & 45.5 & 396.859 & 26,800 & 30 \\
\hline 511.212 & 23,342 & -- & 506.514 & 26,450 & 200 \\
\hline 534.308 & 17,366 & 722.6 & -- & -- & -- \\
\hline 546.576 & 35,337 & 1,474 & -- & -- & -- \\
\hline 567.980 & 33,142 & 567.9 & 578.808 & 34,150 & 400 \\
\hline 586.102 & 29,447 & 333.7 & -- & -- & -- \\
\hline 663.574 & 37,092 & 1,697 & 663.403 & 37,500 & 1900 \\
\hline 713.817 & 44,822 & -- & 713.534 & 44,000 & 180 \\
\hline 756.819 & 35,746 & 3,355 & 756.709 & 37,100 & 3,600 \\
\hline 792.287 & 14,806 & 1,737 & 788.966 & 10,750 & 1,900 \\
\hline 878.156 & 22,260 & 817.7 & 861.651 & 22.680 & 420 \\
\hline 954.737 & 30,329 & 2,729 & 954.783 & 48,900 & 200 \\
\hline 975.377 & 6,471 & 1,493 & 972.216 & 6,080 & 340 \\
\hline
\end{tabular}

Table 2.

\section{CONCLUSIONS}

$\mathrm{X}$-Ray operations have resumed with 4 systems since early January with good results. Injection at $745 \mathrm{MeV}$ and $502 \mathrm{~mA}$ has been achieved during limited study periods. A beam current of $410 \mathrm{~mA}$ has been accelerated to $2.528 \mathrm{GeV}$ with 12 hour lifetime. The lifetime will improve as the ring vacuum conditions at the new higher current. Presently, beam-line shutters and insertion devices (undulators and wigglers) are disabled during these studies because of possible heating due to increased photon power. Calculations are being made to determine operational limits. X-Ray energy has also been ramped to $2.8 \mathrm{GeV}$ with a $20 \mathrm{~mA}$ test current for a radiation survey. Plans for the future are to optimize injection and to determine the RF parameters necessary to reach 500 $\mathrm{mA}$ at $2.5 \mathrm{GeV}$ and $250 \mathrm{~mA}$ at $2.8 \mathrm{GeV}$.

\section{REFERENCES}

[1] NSLS Tech Note \#482 - Higher Order Mode Damping in X-Ray Ring Accelerating Cavity, W. Broome, R. Biscardi - 1993.

[2] S.M. Hanna and P. Stefan, "Application of Impeciance Measurement Techniques to Accelerating Cavity Mode Characterization", submitted to Nucl. Instr. and Meth. in Physics Research, 1993.

[3] S.M. Hanna and P. Stefan, "Characterization of NSLS Accelerating Cavities Using Impedance Measurement Techniques," to be published in the Proc. of the 1993 IEEE Particle Accelerator Conf., 1993. 

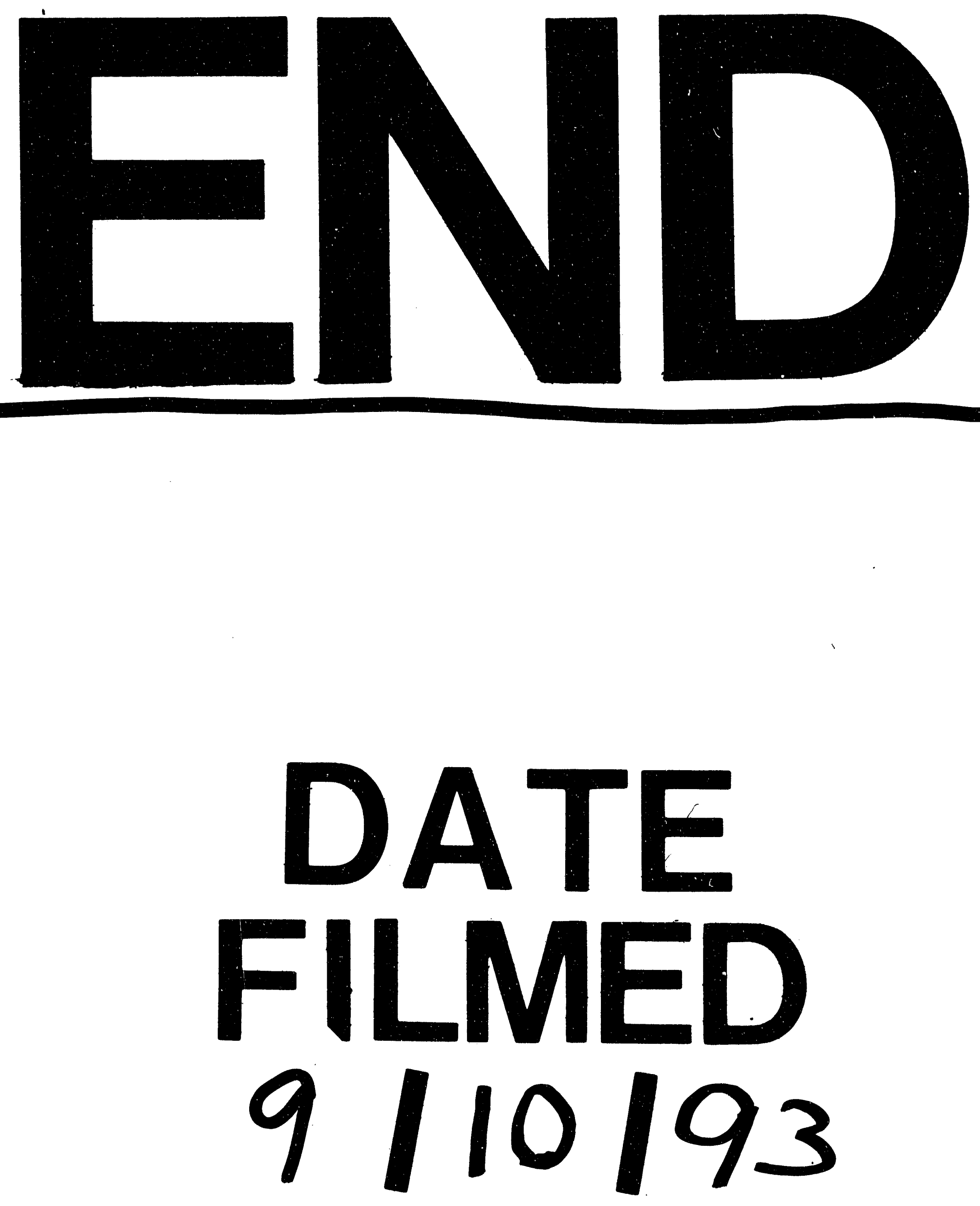
